strument can be wielded with unfortunate results when it is applied to our discipline. Family physicians then become like the confused individual who is told that a zebra must be a tiger because it has vertical stripes, never mind the other differences! I would argue that if a better classification scheme can be developed that is more true to the patients sitting in the "ordinary family practice waiting room," we would be foolhardy to eschew its use.

Donald E. Nease, Jr, MD University of Michigan Health System Ann Arbor

To the Editor: The point Dr. Wahl seems to be making is that experienced family physicians should feel free to direct that experience toward the accurate, naturalistic description of mental illness phenomena in a way which is beneficial for the patient so afflicted. The words and labels used are not only irrelevant, but they can be harmful if they lead to inappropriate treatment or a pessimistic prognosis that is unwarranted. I could not agree more.

Thomas L. Schwenk, MD

University of Michigan Health System Ann Arbor

\section{Screening and Counseling for Down Syndrome}

To the Editor: I found Drs. Cate and Ball's review of screening for Down syndrome (Cate S, Ball S. Multiple marker screening for Down syndrome - Whom should we screen. J Am Board Fam Pract 1999;12:367-74) informative and sensitive. I believe, however, its advice that "pretest counseling should be nondirective" oversimplifies complex and difficult issues.

I have a 16-year-old daughter, Kate, with Down syndrome and have thought long about prenatal diagnosis. Being told that my first-born child would be disabled was terribly painful. Raising her has been a difficult challenge. I know personally the emotional, physical, and financial costs in raising a disabled child. But, as the review suggests, there have also been great gifts. She is a delightful young woman, and she is delighted with herself. In loving her and being loved by her, I have learned that being accomplished is not what makes people worthwhile, that intelligence is not the measure of a person's soul or a person's joy or a person's humanity. In accepting her fully, I have slowly come to accept myself more fully, with all my human flaws and struggles. I lose track of this still, sometimes daily, in our culture that so much judges and values people by their beauty, wealth, and ability. Kate is there every day reminding me, making me smile, a living contradiction to my confusions.

Our technology now allows us to screen fetuses and offer patients the choice of eliminating some who are impaired. If I had been offered this choice with Kate, I don't know what I would have done. I fear I would have been overwhelmed and turned away from having her. That path on its face seems easier, but has a high price the price of knowing every day that I chose to do away with a child of mine rather than accept her. It leaves me less forgiving and accepting of my children, the world, and myself.
I think the counseling of patients regarding prenatal diagnosis (with termination) requires that we direct patients to explore their values about disability and human life. This task is daunting (particularly in a 15-minute visit!). I believe my patients need help at such times to work through their feelings about this very painful prospect and discover their heart's choice. In this counseling I hope to be nonjudgmental and listen well. I also want to challenge assumptions and help them look deeply.

David E. Nicklin, MD

Univeristy of Pennsylvania

Philadelphia

The above letter was referred to the authors of the article in question, who offer the following reply.

To the Editor: We appreciate Dr. Nicklin's personal reflections. We hope our article continues to stimulate discussion about the appropriate application of such screening tests as the multiple marker screening test. In this article we hoped to convey to the busy physician what we believed were the minimum requirements for adequate pretest counseling. It is clear that nondirective counseling is fundamental if a patient is to reach a decision regarding screening that is most consistent with her values and desires. It is also clear from reading the literature that physicians do not do a very good job of this type of counseling. ${ }^{1}$ Our guideline for pretest counseling is intentionally simplified in an effort to assist physicians in trying to fit this discussion into a 15 -minute visit. We agree it is difficult.

Sara Cate, MD
Yakima Valley Memorial Hospital
Susie Ball, MD
Central Washington Family Medicine
Residency Program
Yakima, Wash

\section{References}

1. Braddock $\mathrm{CH} 3 \mathrm{~d}$, Edwards KA, Hasenberg NM, Laidley TL, Levinson W. Informed decision making in outpatient practice: time to get back to basics. JAMA 1999;282:2313 20.

\section{Family Physicians and Firearm Safety Counseling}

To the Editor: Shaughnessy and colleagues, ${ }^{1}$ in their article on family physicians and firearm safety counseling, have clarified a long-neglected question: how do patients view physicians' counseling on firearms?

Patients have good reasons to view such counseling with skepticism. The American Medical Association (AMA), ${ }^{2}$ the American Academy of Pediatrics (AAP), ${ }^{3}$ and the American College of Physicians (ACP) ${ }^{4}$ have all adopted and publicized policies urging more gun control. These policies range from even higher tax burdens on gun owners to support for handgun bans. All these organizations advocate legislation hostile to gun owners.

None of these organizations or physicians firearm experts attempt to reconcile or even acknowledge the existing body of criminology research on firearms. Most 
of this research concludes that gun ownership by mentally competent, noncriminal citizens actually prevents violent crime. $^{s}$

If these organizations were truly concerned with patient safety, we could expect them to collaborate eagerly with established gun owner organizations. The National Rifle Association (NRA), for example, has taught firearm safety for more than a century. The NRA commands great resources and an extensive community outreach for firearm safety education. Still, medical organizations have so far been unwilling to look beyond politics and work with these acknowledged gun safety experts..

But most important, ethical reasons compel physicians to heed the warning of the patients surveyed in this study. The firearm safery counseling advocated by the AMA, AAP, and ACP is a misuse of the patient's trust because its real intent is gun control advocacy. Since relatively few physicians are certified firearms instructors or are otherwise qualified to teach firearm safety, almost all physician firearm counseling falls into this category. Such physician conduct is a violation of ethical boundaries. ${ }^{6}$

The 60 million or more Americans who own firearms are our patients. They generally know more about gun safety than the average physician who does not own a gun. More to the point, they can see when we are mis- using our authority to push a political agenda of gun control. We would be wise to trust their competence and respect their autonomy.

Timothy Wheeler, MD

Doctors for Responsible Gun Ownership Upland, Calif

\section{References}

1. Shaughnessy AF, Cincotta JA, Adelman A. Family practice patients' attitudes toward firearm safety as a preventive medicine issue: a HARTNET study. J Am Board Fam Pract 1999;12:354-9.

2. HELP Network News, Winter/Spring 1998:2. [Published by the Handgun Epidemic Lowering Plan (HELP) Network]

3. American Academy of Pediatrics Committee on Injury and Poison Prevention: Firearm injuries affecting the pediatric population. Pediatrics 1992;89 (4 $\mathrm{Pr}$ 2):788-90.

4. Firearm injury prevention. American College of Physicians. Ann Intern Med 1998;128:236-41.

5. Stolinsky DC, Wheeler TW. Firearms: a handbook for health professionals. Claremont, Calif: The Claremont Institute, 1999. [A summary of current criminology literature on firearms.]

6. Frick $D$. Nonsexual boundary violations in psychiatric treatment. Review of Psychiatry 1997;13:418-9. 